\title{
Teaching for Abstraction: Teacher Learning
}

\author{
Paul White, Sue Wilson \\ Australian Catholic University \\ <paul.white@acu.edu.au; sue.wilson@acu.edu.au> \\ Michael Mitchelmore \\ Macquarie University \\ $<$ mike.mitchelmore@mq.edu.au>
}

\begin{abstract}
Working collaboratively with the researchers, a small team of teachers developed and taught two Grade 6 mathematics lessons based on the Teaching for Abstraction model (White \& Mitchelmore, 2010). This paper reports how one teacher learned about the model and implemented it in practice. It was found that she assimilated several key features of the model, such as starting with several embodiments of the target concept and guiding students to look for similarities between them. However, it was more difficult for her to help students abstract and reify the target concept and link it to other mathematical concepts. It was concluded that teachers also need to abstract Teaching for Abstraction, and need more embodiments of it before they can reify and implement an effective model.
\end{abstract}

Keywords: learning by abstraction, Lesson Study, primary school education, professional growth, teacher learning

Over the past decade, the first and last author have been developing a mathematics teaching model called Teaching for Abstraction which is based on a specific theory of learning mathematics. However, we have repeatedly found that teachers' ability to comprehend the underlying theory has been a barrier to effective implementation. This paper represents an attempt to identify more closely what aspects of the Teaching for Abstraction model teachers find particularly difficult and to design more effective professional development.

\section{Background and Rationale}

\section{Learning by abstraction}

One theory of mathematics learning (Dienes, 1963) holds that all elementary concepts are the result of abstraction and generalisation from common experiences. For example, children experience many objects that are basically linear such as the edge of a table and a line drawn with a ruler. They see that two edges of a table top meet at a corner and they mark points on a drawn line to indicate a particular length. However, they also experience objects that are too wide, curved or indistinct to be called a line (such as a path across a field) and other lines that do not meet at a point (such as railway tracks). By recognising the underlying similarity among the first category of experiences, and differences with the second category, 
children may abstract the concepts of line, point and intersection and generalise that two lines never meet in more than one point.

The role of abstraction in this theory of learning was well described by Skemp (1986) as follows:

\begin{abstract}
ing is an activity by which we become aware of similarities ... among our experiences. Classifying means collecting together our experiences on the basis of these similarities. An abstraction is some kind of lasting change, the result of abstracting, which enables us to recognise new experiences as having the similarities of an already formed class. ... To distinguish between abstracting as an activity and abstraction as its endproduct, we shall ... call the latter a concept. (p. 21, italics in original)
\end{abstract}

We call the formation of basic mathematical concepts in this manner empirical abstraction because it is based on experience.

Empirical abstraction occurs both inside and outside the classroom. For example, parents often help young children recognise similarities in their everyday experiences (e.g., by teaching them the names of particular classes of objects) and school children frequently look for patterns that could simplify their learning (“Just tell us the rule, miss!”). Such empirical abstraction is almost always superficial. Everyday concepts such as "red" and "building” are based on surface appearances anyway, so they are necessarily superficial. But mathematical concepts are based on deeper similarities and it is important that these deeper similarities be learned (Mitchelmore, 2000). For example, students must go beyond thinking that a fraction is "one number over another".

Empirical abstraction is to be contrasted with theoretical abstraction, which is the construction of concepts to fit into a specific mathematical theory (Davidov, 1990). For example, the mathematical concepts of line and point are theoretical abstractions; their only existence is in terms of axioms (such as "two lines never meet in more than one point”) that define relations between them and other geometrical concepts. Reasoning about theoretical points and lines must be based on such precise axioms, and no appeal can be made to the imprecise points and lines of experience. Theoretical abstraction plays an extremely important role in mathematics.

We have argued (Mitchelmore \& White, 2004) that most abstract mathematical theories are constructed to model empirical abstractions. For example, theoretical lines and points only represent real linear objects and points - there is no such things in our world as a perfectly straight line or a dimensionless dot. It is not until one reaches the refined atmosphere of research mathematics that theories are invented for their own sake, but even they can be traced back through a succession of theories to some aspect of our experience. 
Therefore, if students are to appreciate the value of theoretical mathematics and be able to apply abstract theory to concrete situations, they need to have a sound understanding of the empirical abstractions on which the theoretical abstractions are based.

\section{Teaching For Abstraction}

Teaching for Abstraction (White \& Mitchelmore, 2010) attempts to build on children’s natural tendency to seek similarities and make rules in order to assist them to abstract mathematical concepts. The Teaching for Abstraction model consists of four phases:

1. Familiarity. Students explore a variety of contexts where a concept arises, in order to form generalisations about individual contexts and thus become familiar with the underlying structure of each context.

2. Similarity. Teaching then focuses on helping students recognise the similarities and differences between the underlying structures of these various contexts.

3. Reification. The general principles underpinning the identified similarities are drawn out, and students are supported to abstract the desired concept into a mental object that can be operated on in its own right.

4. Application. Students are then directed to new situations where they can use the concept.

In this model, teachers start by carefully selecting situations known to the students that embody a significant mathematical concept and ensure that students understand the mathematics within each situation. They then deliberately focus students' attention on the underlying similarity between those situations and help them formulate that similarity in abstract terms. Finally, they help students learn how to operate with those abstract concepts and apply them to solve problems in other situations that embody that concept. Several examples of specific skills and understandings at each level of the model are given in White and Mitchelmore (2010).

The model is the reverse of the traditional ABC (Abstract Before Concrete) method of teaching mathematics (Mitchelmore \& White, 2000). As one teacher put it, "It is the opposite of what we're doing in school now. It is starting with the blurred and being revealed. Backwards. Not doing specific instructions first, more a thinking thing.”The model has many similarities to several approaches advanced in the mathematics education literature over the past 20 years (encapsulated in such slogans as realistic learning, communities of discourse, and teaching for understanding) in its emphasis on drawing mathematics out of familiar contexts through teacher-guided exploration and reflection. The major difference lies in the 
relation posited between abstract ideas and familiar experience: Concepts are seen as representing what is common among several experiences, rather than as ideas that can be explained or justified through specific experiences. As a result, Teaching for Abstraction uses multiple contexts for each concept, focuses on the relation between them, and constantly links abstract ideas to the several contexts from which they were derived.

Our earliest experiments with the Teaching for Abstraction model involved teaching the concept of angle in Years 3 and 4 (Mitchelmore \& White, 2002a, 2002b). Familiar contexts included corners, scissors, body joints, doors, clock hands, and slopes. The first lessons concentrated on ensuring that students understood each of these contexts to the extent that they could represent them graphically (Phase 1: Familiarity). The next lessons involved a variety of matching exercises, both within and between contexts, leading students to recognise that an angle (wherever it occurred) had two arms meeting at a point and that each angle had a particular size (Phase 2: Similarity). Students then completed various activities to develop facility in interpreting and using abstract angle diagrams (Stage 3: Reification) and using them in new situations (Phase 4: Application). There was evidence that many students developed a quite sophisticated concept of angle by as early as age 10 .

Subsequent experiments have investigated the teaching of decimals, percentage and ratio by abstraction. Summaries of these experiments and their effectiveness are given in White and Mitchelmore (2010). The investigations have confirmed our conviction that the Teaching for Abstraction model has promise in terms of student learning of key concepts and generalisations. They have also consistently shown the vital significance of teacher learning.

\section{Teacher learning}

In the teaching studies we have undertaken, we have provided teachers with detailed lesson outlines but many teachers have found it difficult to implement the Teaching for Abstraction model. Because the model is so different from common teaching practice, we have found it difficult to communicate to teachers despite revising the professional learning activities several times. As a result, many teachers have either followed the materials provided to the letter, not being in a position to adapt them to their particular classroom situation, or they have subverted the whole process and reverted to the ABC method. As a result, the model was not implemented faithfully in several of the classrooms we studied. Nevertheless, most teachers have spoken favourably of the results in their classrooms, and some have expressed the wish for further materials. 
A possible reason for the poor implementation of the model in previous studies is that the teachers were not involved in planning the unit or developing the teaching materials. The literature on teacher learning repeatedly cites the importance of active teacher involvement if innovative ideas are to be accepted (Pegg \& Panizzon, 2008). In our investigations, the researchers did all the development and simply presented lesson plans to the teachers. Consequently, the teachers had no real ownership of the experiments. They may even have considered us as outsiders with no knowledge of classroom realities (Jaworski, 2004).

We therefore decided to investigate a different method of implementing Teaching for Abstraction, one in which, instead of presenting teachers with completed teaching materials, we would work collaboratively with teachers to develop Teaching for Abstraction lessons that would better fit their own classroom situations. We hypothesised that such a procedure would lead to greater ownership and thus more faithful implementation, deeper student learning and, most importantly, greater teacher learning than the previous method.

\section{The present study}

As a theoretical framework for assessing the impact of this new method of professional development, we call on the Interconnected Model of Professional Growth (Clarke \& Hollingsworth, 2002). This model contains four domains and various interactions between them, as shown in Figure 1. Note that most interactions are bidirectional. For example, teachers enact a new idea, belief or practice in their classroom and then reflection provides (positive or negative) feedback on the critical features of that innovation and its value to them.

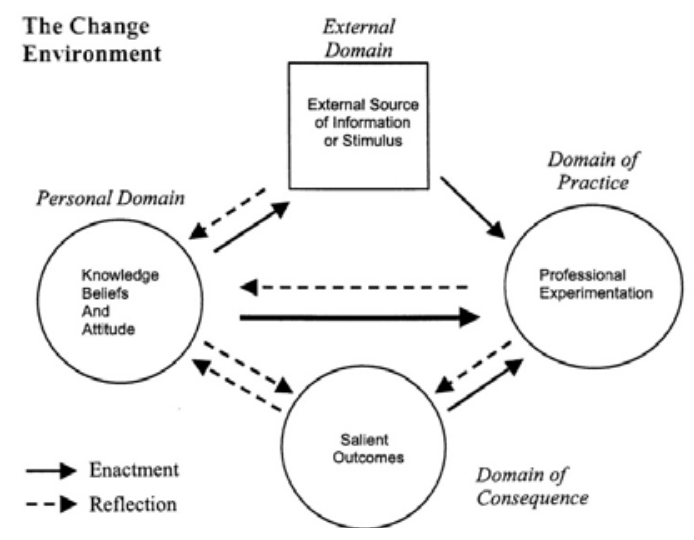

Figure 1. The Interconnected Model of Professional Growth (reproduced by permission from Clarke \& Hollingsworth, 2002). 
As an initial exploratory study, we worked with a small group of teachers in a small regional town to prepare two unconnected lessons. The teachers then taught these lessons in a kind of lesson study mode (Hart, Alston, \& Murata, 2011). In terms of Figure 1, the External Domain was the collaborative lesson preparation and study, the Personal Domain was teachers' knowledge and acceptance of Teaching for Abstraction, the Domain of Practice was the lessons taught, and the Domain of Consequence consisted of student outcomes from the lessons taught.

Our research question was: Can collaborative lesson development lead to faithful implementation of the Teaching for Abstraction model?

More specifically: Which parts of the model are easier or more difficult for teachers to implement? Can student learning be linked to the parts of the model that are implemented?

To provide answers to these questions, data were collected on all four components of the model in Figure 1. We report a case study of one of the teachers involved.

\section{Method}

\section{Participants}

The study took place in Grade 6 at St Joseph's ${ }^{1}$, a small primary school in regional New South Wales. Initially, three teachers volunteered to participate: David, Bridget, and Uarda. However, David was unwell during our visits and only participated marginally. Also, Bridget was a part-time teacher and had several other calls on her time. Only Uarda participated fully, and she is therefore the focus of this paper. Uarda had been teaching for 5 years, and was enrolled in a master's degree at the time.

\section{Procedures}

The authors paid two 2-day visits to St Joseph's. Both visits followed the same pattern: The research team (the authors, Uarda, and whichever of the other teachers were available) met for an initial discussion on the afternoon of Day 1 to decide on the aims for the following day. Early on Day 2, the team developed a lesson and prepared the necessary materials. Both sessions were guided by the principle that each participant should contribute their particular expertise in the lesson design. Thus, the authors shared their knowledge of the Teaching for Abstraction Model and their experience of its previous implementations while the teachers contributed their knowledge of the school curriculum and their students. 
Later in Day 2, Uarda taught the experimental lesson while the others observed, after which the team discussed the lesson and modified it as they felt appropriate. Bridget then taught the revised lesson while the others observed. On the second visit, an additional team session was devoted to identifying the strengths and weaknesses of the Teaching for Abstraction model and reflecting on the teacher learning that had occurred.

After the second visit, Uarda indicated that she would attempt to apply the model to her teaching about angles in the following month. After teaching this unit, which we did not observe, she provided the authors with written feedback.

\section{Data collection and analysis}

The research team's discussion sessions were audio recorded and transcribed, but no recordings were made of the lessons. Instead, one member of the research team acted as a lesson recorder, taking detailed notes of the lessons that included time markers for the major transitions. The other members subsequently added their individual observations to these notes.

Because student outcomes have a significant feedback effect on teacher learning (Clusky, 2002), an attempt was also made to assess short-term student learning. The recorder noted students' comments during the face-to-face teaching and all members of the team circulated and observed students during the small group work, occasionally interacting with them to clarify what they were attempting to do. In addition, the teachers administered a short quiz at the end of the first visit and a short questionnaire at the end of the second visit.

The analysis of how Uarda interpreted and applied the Teaching for Abstraction model, as well as its resulting effectiveness and potential, focussed on the four components shown in Figure 1. Firstly, each author formed an interpretation of each of these components on the basis of their own observations, notes and informal discussions during the site visits. The three authors then cross-validated and synthesised their separate interpretations during extensive discussions, frequently re-examining transcripts and field notes to reach consensus.

\section{Results}

\section{The first visit}

Initial discussions. At the first meeting of the research team, the authors outlined the Teaching for Abstraction model and gave some examples from their previous research. In particular, they provided the teachers with copies of the instructional materials developed for a previous Grade 6 percentages investigation (White, Mitchelmore, Wilson, \& Faragher, 
2008). They also explained the purpose of the study, and asked teachers for their reaction to the model and its potential in their situation.

The teachers expressed interest in experimenting with the model. Uarda indicated that she regularly trialled novel activities and approaches that she believed might be beneficial to her students. Teaching for Abstraction had a definite resonance for her because she was particularly keen on the use of realistic scenarios and always tried to embed the mathematics she was teaching in contexts that she felt would be familiar to students.

The teachers then outlined a number of topics where they felt their students were having most difficulty, and it was agreed that the next day's lesson would focus on place value in decimals. It was also agreed that Uarda and Bridget would both teach the same lesson with their own classes, in that order, with time for discussion and revision between the two lessons.

Lesson planning. The teachers reported that students had been taught about decimals but some students were still having difficulty deciding, for example, whether 0.65 was bigger than 0.8. It was decided to focus the lesson on this topic, restricting the content to 1- and 2place decimals. It was considered that this topic was sufficiently narrow for a single lesson, but that it could nevertheless be of significant value to students. The teachers could extend students' understanding to other decimals later.

Having decided on this topic, that next task was to identify a small number of familiar contexts involving one- or two-place decimals, which could then be compared to identify and abstract the underlying similarity. The teachers initially had some difficulty with this task but, after some suggestions from the authors, the team agreed on four contexts: money ( $\$ 0.65$ vs $\$ 0.8$ ), length ( $0.65 \mathrm{~cm}$ vs $0.8 \mathrm{~cm}$ ), fractions of a box of 100 lollies ( $0.65 \mathrm{vs} 0.8$ ), and fractions of a $10 \times 10$ square of chocolate ( 0.65 vs 0.8 ). It was decided to write four scenarios and to break each class into four groups that would (after an initial introduction) circulate around the four tasks, spending no more than 5 minutes on each. This would leave time for a final discussion of students' responses in which generalisations about decimal place value could be abstracted.

It was agreed that the planned lesson included the first three phases of the Teaching for Abstraction model applied to the concept of decimal place value: Students were already familiar with the four contexts, they would be prompted to identify the underlying similarities between them, and generalisation would initiate reification. Application would occur in subsequent lessons. 
The teachers then left to collect or create materials for the lesson (counters for money and lollies, rulers and butcher paper for measurement, and grids for the chocolate). After they returned, discussion continued on the phrasing of the actual tasks to be used. The entire planning session took just under an hour.

The lesson. Uarda started the lesson by writing the four scenarios on the whiteboard (see Figure 2). She explained the rotation procedure for the lesson (which was already familiar practice in her classroom), divided the students into four approximately equally sized groups, and instructed them to start working on their first scenario. No other introduction was given.

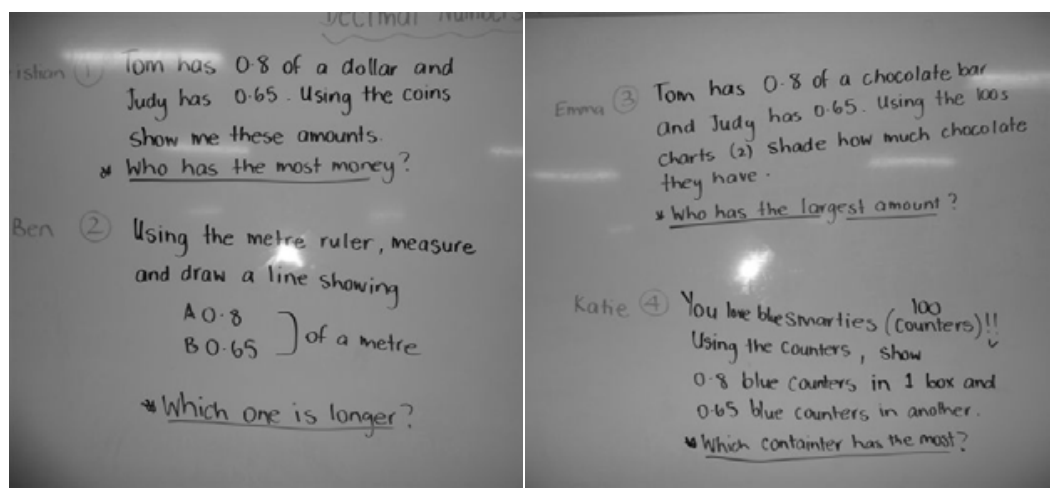

Figure 2.Scenarios for the first trial lesson.

During the small group work (see Figure 3), the group working on the money task finished first at each rotation. The lollies group took a long time to count out two lots of 100 counters, and the measurement group was slow to draw their two lines. Although the first rotation took only 3 minutes, as planned, the group work took up 26 minutes in all because of the slowness of groups working on the lollies and measurement scenarios. 


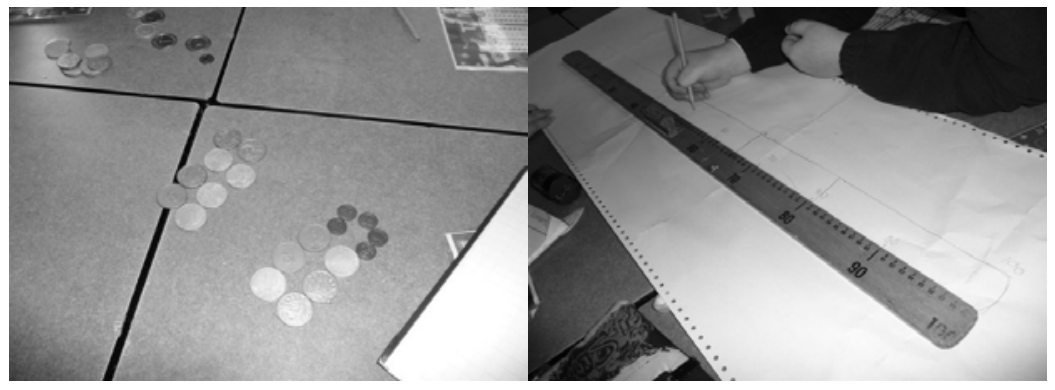

(1) Money task

(2) Measurement task

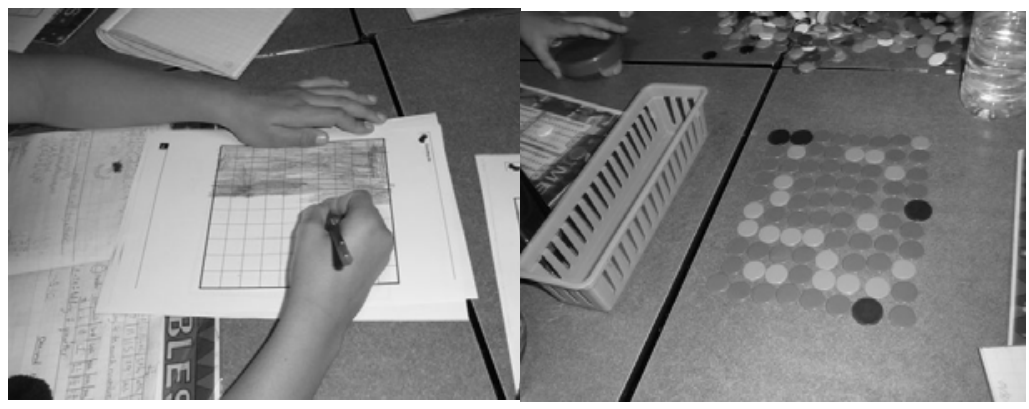

(3) Chocolate bar task

(4) Lollies task

Figure 3.Students' work on the four tasks.

Uarda then commenced the final discussion section of the lesson. Asked to identify similarities between the four scenarios, students initially remarked only on superficial aspects: They all involved Tom and Judy and the numbers 0.8 and 0.65, and Tom always won. Asked how we know that 0.8 is bigger than 0.65 , some students demonstrated considerable insight with the responses " 0.8 is 0.80 ", " 0.65 is 6 and a half, whereas 0.8 is 8 " and " 0.8 is different from 0.08”. Uarda then gave an explanation using Dienes blocks, taking the flat to represent 1 unit and having the students recognise that a long then represents 0.1 and a cube represents 0.01 . Many students appeared to realise that 0.8 is represented by 8 longs and that 0.65 corresponds to 6 longs and 5 cubes, but others appeared bewildered. One student suggested that a cube represented 0.1 and several students called 0.65 "point sixtyfive".

Lesson discussion. After the lesson, Uarda remarked on how well the students enjoyed the hands-on aspect of the lesson. She was particularly struck by the fact that some students who are normally silent had participated actively: "Monica put up her hand at the 
back a few times. She's somebody that generally has no idea. And she was hands up confidence. ... She was the one that was explaining when the boy beside her wasn't sure.”

Students' tendency to notice irrelevant similarities was noted, and the authors recalled Dienes's (1963) dictum that "all variables need to be varied if the full generality of the concept is to be achieved” (p. 158). It was decided for the second trial lesson to vary the children's names and to ask alternately for the larger or smaller number. It was also decided to compare 0.4 and 0.25 in order to make the lollies and measurement tasks more manageable. Bridget left to write the revised scenarios on the whiteboard in her classroom in preparation for the second lesson.

Discussion then turned to the question of how general students' understanding of place value was. In particular, it was felt that the approach taken had tended to reinforce whole number thinking (e.g., treating 0.8 as 80 out of 100 rather than a fraction of the flat). It was decided to put more emphasis on decimals as fractions of a whole rather than numbers of parts of the whole, even by including questions such as "What is 0.8 of a student's pony tail?" Ideas were canvassed on how to question students in order to take them beyond the specific insights they had shown, by focussing more strongly on the similarities between the four scenarios. The plan for the repeat lesson (not reported here) was modified accordingly.

As a measure of how much students had learned from the lesson, Uarda suggested a short quiz in which students would be asked to identify the smaller of two decimals; the team then constructed this quiz jointly. Figure 4 shows the resulting quiz.

Circle the smaller number:
(1) 0.8
(2) 0.52
(3) 0.6
(4) 0.8
(5) 1.6534
(6) 2
0.65
0.7
0.298
0.09
1.72
2.2

Figure 4.Short quiz questions.

Assessment. Shortly after the lesson discussion, Uarda administered the quiz to a total of 24 students in her class. About 70\% answered Items 1, 2 and 6 correctly, while Items 3, 4 and 5 were only answered correctly by just over $50 \%$ of the students. However, it was noted that five students marked all the larger numbers correctly. It could be argued that they understood how to find the larger or smaller of two decimals, but had not read the 
instructions carefully and had proceeded as in the scenarios they had just experienced. On this assumption, the percentages correct would have been about $20 \%$ greater.

If this assumption is correct, the result for Item 2 would suggest that the majority of Uarda's students had generalised their knowledge of 2-place decimals to numbers other than the ones in the given scenarios. However, the zero in Item 4 seems to have introduced problems for several students. Most students appeared to be able to cope with numbers with no decimal places, as in Item 6, but it was clear from Items 3 and 4 that more work needed to be done on decimals with more than 2 places.

In general, the assessment results confirm the post-lesson discussion that greater emphasis needed to be put on bringing out the underlying structure of the decimal notation system.

\section{The second visit}

Initial discussions. The teachers had decided that on this occasion they wanted the lesson to focus on percentages, where students were demonstrating continued difficulties. The team brainstormed some typical percentage problems and possible scenarios, gradually honing in on discounts and the generalisation "a percentage must be a percentage of something”. After some discussion of how to approach this generalisation, it was agreed to present two scenarios that consisted of specific calculations from which the generalisation could be abstracted and two applications of the generalisation where no calculation was specified. Students would be asked to predict the answers before doing the calculation in the first type of scenario, and the two types of scenario would be separated by a brief discussion.

It was agreed that this lesson followed the Teaching for Abstraction model. Students would learn the percentage generalisation by recognising the similarity between the two initial scenarios, which would have to be chosen to be familiar. They would then be prompted to apply the generalisation to two different contexts.

Uarda also suggested a "cognitive closure" exercise at the end of the lesson, to check student understanding. Apart from this, it was agreed to follow the same procedure as on the previous visit.

Lesson planning. Four scenarios were composed; ensuring that Scenarios 1 and 2 gave contrasting results. Figure 5 shows the four scenarios. Each scenario was written on an A5 card (two copies of each), and the words “Don't forget to predict which will be the better deal before calculating” were written in capitals on each card for Scenarios 1 and 2. No 
materials were required for this lesson, but David created an A3 illustration to motivate each scenario.

1. There are 2 telephone plans and your parents are going to give you a \% (percentage) of money towards your plan. In which plan do your parents give YOU more money?
(a) $\quad 15 \%$ on $\$ 50$ plan
(b) $10 \%$ on $\$ 60$ plan

2. Electronic Store A is having their $50 \%$ mid year sale. Your favourite game is usually $\$ 110$. How much will you pay now?

At Electronic Store B, the full price for your favourite game is usually $\$ 90$. Their discount is $40 \%$. How much will you now pay?

Which shop is offering the better price?

3. Pizzas Galore have a $10 \%$ surcharge on all of their purchases on a Sunday. You want 3 pizzas. Is it cheaper to buy the 3 at once or one at a time?

4. The top 2 basketball teams of the local basketball league have a success rate at goal shooting of $80 \%$ and $50 \%$.

Which team has shot the most goals in the season?

Figure 5.Scenarios for the second trial lesson.

The lesson. Uarda began the lesson by teaching students how to use a calculator, writing the examples in Figure 6 on the whiteboard and giving students three examples of each type to work out. However, some students seemed to be working out the percentages mentally, and many found the resulting price by subtracting the discount from the original price instead of using the second procedure.

$\begin{array}{lll}50 \times 25 \% & = & \text { [gives a } 25 \% \text { discount on \$50] } \\ 50 \times 25 \%- & = & \text { [gives the resulting price] }\end{array}$

Figure 6.Uarda’s examples of using a calculator for percentages.

Fifteen minutes into the lesson, Uarda introduced the first two scenarios and explained the rotation procedure. In one group, students' predictions appeared to be mere guesses. Calculation difficulties (which button to press) seemed to distract from understanding, and several students did not seem to realise the difference between discount and discounted price. In one group, two students showed the others how to do the calculations and told them the answers. After 13 minutes on these scenarios, Uarda's question "What surprised you?” led to 
vigorous discussion and general agreement that the bigger percentage does not always give the bigger amount.

Thirty-three minutes into the lesson, students started on the second pair of scenarios. Scenario 3 seemed rather difficult, the idea of checking a prediction by choosing values being clearly unfamiliar to the students. The term "surcharge" was also unfamiliar to several students. Scenario 4 seemed to be much easier, even though it also requires the choice of specific values to test a generalisation.

There was only time at the end of this lesson to check students' answers and discuss how to test general predictions. Several students successfully argued in Scenario 3 that "it doesn't matter”, but one student was adamant that buying three separate pizzas would be cheaper and could not be dissuaded from this view.

Lesson discussion. It was generally agreed that, in this lesson, students had been absorbed with the procedure for using a calculator and that this had interfered with the cognitive process of generalisation. Uarda said that, in future, she would break down the content into several lessons_-perhaps mastering the method of calculation and a lesson on discounts and surcharges before posing the problems in Scenarios 1 and 2. She would then take a whole lesson on Scenarios 3 and 4.

A number of minor points were also identified. For example, it was agreed that including the instruction "Give an example to illustrate your thinking” would help students in responding to Scenarios 3 and 4 . Minor changes were made for the repeat lesson (not reported here).

Assessment. Figure 7 shows the cognitive closure exercise that Uarda constructed and administered shortly after teaching her lesson. Responses were obtained from 17 of her students.

By completing these 4 exercises, what have you learnt about \% (percentages)?

Give me an example of your own.

Figure 7. Cognitive closure exercise.

Responses to the first question were grouped into seven categories, with some students giving responses in more than one category. Almost 50\% of the students responded to the effect that "the smaller percentage doesn't always make the smaller answer" and $40 \%$ indicated that they found the scenarios thought provoking and requiring different procedures for different questions. Smaller percentages (less than $20 \%$ in each case) stated that they use 
percentages every day or that they had learnt nothing new, or gave a small number of other responses.

Students' examples were categorised as direct or open, contextual or abstract, and calculation or comparison. Nearly $50 \%$ fell into the direct contextual comparison category similar to Scenarios 1 and 2 and less than 25\% involved an open contextual comparison as in Scenarios 3 and 4.

These results were considered encouraging, the categories of examples proposed by students apparently reflecting their greater familiarity with the style of Scenarios 1 and 2.

\section{Follow-up}

About a month after our second visit, Uarda taught an angles unit which she had designed following the principles she had learnt during our earlier visits. The key ideas addressed over four lessons were as follows (quoting from the unit outline she provided): Angles are found everywhere; angles can be measured using a protractor; parallel lines have equal angles; and each type of angle is useful. Apart from angle measurement, where Uarda first showed students how to use a protractor, the lesson plans showed a similar procedure to the earlier trial lessons: Activities in small rotational groups were followed by class discussion and some follow-up tasks. For example, the four activities used in the first lesson were as follows:

1. Find angles around the room.

2. Make as many angles with scissors.

3. Make as many angles with straws.

4. Draw as many different angles as you can using a ruler.

The follow-up task was:

Draw 6 different angles in your books. How are they different? When are they used? Where do you think you could find these angles at home?

Uarda made the following comments on this unit:

I think the program worked well. I used the small group work again and immersed them in different contexts wherever I could. The planning was probably slightly quicker as I didn't need to spend time with the explicitly teaching section as such, but more so on thinking about questions to ask to find generalisations of their findings and more [on] the context and content I wanted to teach.

I gave them a standard angles test and the only area they struggled in was accurately measuring the angles using a protractor.

We still find that the discussion taking place with this set-up is very positive and it also seems to cater for the differing abilities in the class. ... This kind of context allows the children to extend themselves and "think outside the square" and make connections to the real world. 
Uarda's approach shows several features of the Teaching for Abstraction model: She started with several familiar contexts that incorporated the ideas she wanted to teach and used discussion to draw out underlying generalisations. The follow-up tasks definitely tested children's understanding of the abstract ideas that had been discussed. However, one feature of Teaching for Abstraction did not seem to be present: the search for underlying similarities between the contexts studied. The concepts students learned were common to all the contexts studied; but there was no sign that Uarda had addressed this point in the same way as, for example, is done in the angles unit distributed by the New South Wales Department of Education and Training (2003), which is based on our earlier experiments.

\section{Discussion}

We discuss the results in terms of the four components of the Integrated Model of Teacher Professional Development (Figure 1).

\section{The Domain of Practice: Implementation of the Teaching for Abstraction model}

The two lessons certainly incorporated major elements of the Teaching for Abstraction model. Most obvious was the emphasis on exploring a variety of contexts where a concept arises (Phase 1 of the model). Both lessons were the result of careful planning, firstly to clearly identify a focus concept or generalisation and secondly to select scenarios that embodied this abstraction and would be familiar to the students. However, although students did indeed seem to be quite familiar with all the contexts chosen, in the second lesson calculator difficulties meant that several students could not operate fluently within the discount context.

Similarity recognition (Phase 2) was also present. In the first lesson, students showed a strong tendency to focus on superficial similarities, and it was difficult for Uarda to bring students' attention to mathematical similarities. However, in the second lesson, the question “What surprised you?” did seem to focus students' attention on a generalisation that was implicit in the two scenarios investigated—in this case, the result of recognising a difference rather than a similarity.

Neither lesson proceeded very far with Reification (Phase 3), where the underlying structure could have been laid bare, explained, and formalised. The attempt to use Dienes blocks to explain place value in the first lesson did not seem to relate well to the similarities that students had observed previously. In the second lesson, pressure of time prevented a 
proper exploration of the target generalisation that could have extended it from the specific context of discounts to the general context of abstract percentages.

Phase 4 of the model, Application, was deliberately avoided in the first lesson but did occur in the second lesson (see Figure 5, Items 3 and 4). However, as Uarda noted, it would have been better to give more time to elucidating the percentage generalisation before attempting to apply it.

\section{The Domain of Consequence: Student outcomes}

The assessment of student outcomes for the first lesson suggested that most students had achieved the narrow objective of ordering one- and two-place decimals. However, understanding was not deep enough to allow many students to extend this knowledge to decimals with more than two places or containing zeros after the decimal point. We attribute this finding to shortcomings in the Similarity and Reification phases of the lesson.

The second lesson did not appear to be so successful in terms of student learning, but the results of the cognitive closure exercise showed that many students had learnt the target generalisation.

The two lessons had some other positive outcomes. The realistic nature of the activities in the first lesson appeared to engage students more than usual, and many students appreciated the challenging nature of the second lesson. Throughout, there was clear evidence that students were responding well to the chance to think for themselves and were learning some significant ideas.

\section{The Personal Domain: Teacher learning}

Uarda emphasised right from the first meeting her belief in the importance of embedding mathematics in realistic, familiar contexts. However, the idea of using more than one context for each concept was clearly new to her, and in the initial discussion sessions the authors had to repeatedly stress the importance of similarity recognition in the Teaching for Abstraction model. Consequently, she put a lot of thought and effort into the process of identifying and selecting appropriate contexts for the two trial lessons and used the same principle in her follow-up lesson on angles. Our observations showed that she was skilled in managing a classroom so that students could work on several contexts in one lesson. We conclude that Uarda had successively learned to implement the Familiarity phase of the Teaching for Abstraction model. 
Uarda also attempted to implement the Similarity phase in that she challenged students to identify similarities in, and make generalisations from the exploratory activities they had just carried out. However, she did not clearly distinguish superficial and mathematical similarities and did not probe for explanations or forge meaningful links to students' existing knowledge. For a similar reason, Uarda did not effectively address the Reification phase in either lesson. The little evidence we have from her follow-up lesson confirms that she had formed no clear concept of the content and purpose of these two phases.

Uarda tended to adopt a didactic mode by presenting her own explanations or procedures. For example, neither the use of Dienes blocks in the first lesson nor the use of calculators in the second lesson had been discussed in the lesson planning sessions. These were honest attempts to address known student difficulties, but they only served to disrupt the structure of the Teaching for Abstraction lesson. In this respect, Uarda's modifications were similar to the way teachers in earlier studies had subverted the model by returning to a more familiar lesson structure (White \& Mitchelmore, 2010).

For time reasons, it was not possible to judge how Uarda would have treated the Application phase.

\section{The External Domain: Collaborative lesson planning}

The collaborative lesson planning went according to plan, although it would certainly have been more effective had all the teachers been able to participate to the extent that Uarda did. There is no doubt that she had ownership of the plan for her lessons.

However, it is now clear that the professional development we provided for Uarda and her colleagues did not stress strongly enough the significance of the crucial steps of similarity recognition and reification. It is clear in hindsight that the teachers needed to spend more time reflecting on mathematical similarities - how to distinguish them from superficial similarities, how to draw them out through careful questioning, how to derive adequate explanations, how to link students' learning to their previous knowledge, and how to reify similarities to allow for the abstract manipulation of mathematical concepts. 


\section{Conclusions}

To answer our research questions, then, it appears that collaborative lesson development of the type we provided did not lead to faithful implementation of the Teaching for Abstraction model. In particular, there were serious difficulties in implementing the Similarityand Reification phases of the model. As a consequence, although students gained from the use of familiar contexts and the challenge of reaching their own conclusions, it seems that they did not reach the desired depth of understanding.

Because most modern curriculum innovations stress the importance of linking abstract concepts to familiar situations, it appears to be relatively easy for teachers to learn the Familiarity phases of the Teaching for Abstraction model. However, the Similarity and Reification phases are unique to the model, and are therefore likely to be completely novel to teachers. As Sullivan, Clarke, \& Clarke (2009) found in a similar context, teachers may need a lot of help in developing the new skills required to implement these two phases effectively.

We conclude once again that the type of one-off intervention that was the subject of the present study is unlikely to achieve the desired effects. More time is needed for teachers to experiment with the new lesson structure and to reflect on the results in the classroom. A successful professional development would need to allow teachers to experience more examples of Teaching for Abstraction than the two we were able to provide in this study. They would then be better able to recognise the underlying structure of the model, reify it into a set of principles to be followed, and apply their understanding to the design of new lessons. In other words, we probably need to teach teachers Teaching for Abstraction by abstraction.

\section{Acknowledgements}

The study reported in this paper was supported by a grant from the National Centre of Science, Information and Communication Technology, and Mathematics Education for Rural and Regional Australia (SiMERR).

Notes ${ }^{1}$ The names of the school, teachers and students in this paper are all pseudonyms. 


\section{References}

Clarke, D., \& Hollingsworth, H. (2002). Elaborating a model of teacher professional growth. Teaching and Teacher Education, 18, 947-967.

Cluskey, T. R. (2002). Professional development and teacher change. Teachers and Teaching: Theory and Practice, 8, 381-391.

Davidov, V. V. (1990). Types of generalisation in instruction: Logical and psychological problems in the structuring of school curricula. Reston, VA: National Council of Teachers of Mathematics.

Dienes, Z. P. (1963). An experimental study of mathematics-learning. London: Hutchinson.

Hart, L. C., Alston, A. S., \& Murata, A. (Eds.).(2011). Lesson study research and practice in mathematics education: Learning together. New York: Springer.

Jaworski, B. (2004). Insiders and outsiders in mathematics teaching development: The design and study of classroom activity. Research in Mathematics Education, 6, 3-22.

Mitchelmore, M. C. (2000). Empirical is not mathematical! Reflections, 25(2), 13-15.

Mitchelmore, M. C., \& White, P. (2000). Teaching for abstraction: Reconstructing constructivism. In J. Bana \& A. Chapman (Eds.), Mathematics education beyond 2000 (Proceedings of the 23rd annual conference of the Mathematics Education Research Group of Australasia, pp. 432-439). Perth: MERGA.

Mitchelmore, M. C., \& White, P. (2002a). Teaching angles by abstraction: A professional development experiment in Year 3. Unpublished report, New South Wales Department of Education and Training, Sydney. Retrieved 5 May 2011 from http:// www.curriculumsupport.education.nsw.gov.au/primary/mathematics/assets/pdf/angles_r eport01.pdf

Mitchelmore, M. C., \& White, P. (2002b). Teaching angles by abstraction: A second professional development experiment. Unpublished report, New South Wales Department of Education and Training, Sydney. Retrieved 5 May 2011 from http://www.curriculumsupport.education.nsw.gov.au/primary/mathematics/assets/pdf/an gles_rep2002.pdf

Mitchelmore, M. C., \& White, P. (2004). Abstraction in mathematics and mathematics learning. In In M. J. Høines\& A. B. Fuglestad (Eds.), Proceedings of the 28th annual conference of the International Group for the Psychology of Mathematics Education (Vol. 3, pp. 329-336). Bergen, Norway: Program Committee.

New South Wales Department of Education and Training. (2003). Teaching about angles: Stage 2. Ryde, NSW: Author.

Pegg, J., \&Panizzon, D. (2008). Addressing changing assessment agendas: Impact of professional development on secondary mathematics teachers in NSW. Mathematics Teacher Education and Development, 9, 66-80.

Skemp, R. (1986). The psychology of learning mathematics. $\left(2^{\text {nd }}\right.$ ed.) Harmondsworth: Penguin.

Sullivan, P., Clarke, D., \& Clarke, B. (2009). Converting mathematics tasks to learning opportunities: An important aspect of knowledge for mathematics teaching. Mathematics Education Research Journal, 21, 85-105.

White, P., \& Mitchelmore, M. C. (2010). Teaching for abstraction: A model. Mathematical Thinking and Learning, 12, 205-226.

White, P., Mitchelmore, M. C., Wilson, S., \& Faragher, R. (2008). Teaching percentages: Professional learning in three regional Catholic schools. Journal of Catholic School Studies, 80(2), 55-62. 